\title{
An Exact Solution of MHD Boundary Layer Flow of Dusty Fluid over a Stretching Surface
}

\author{
Mudassar Jalil, ${ }^{1}$ Saleem Asghar, ${ }^{1,2}$ and Shagufta Yasmeen ${ }^{1}$ \\ ${ }^{1}$ Department of Mathematics, COMSATS Institute of Information Technology, Park Road, Chak Shahzad, Islamabad 44000, Pakistan \\ ${ }^{2}$ Nonlinear Analysis and Applied Mathematics (NAAM) Research Group, Faculty of Science, King Abdulaziz University, \\ P.O. Box 80203, Jeddah 21589, Saudi Arabia
}

Correspondence should be addressed to Mudassar Jalil; mudassarjalil@yahoo.com

Received 12 October 2016; Accepted 8 February 2017; Published 6 March 2017

Academic Editor: Nicolas Gourdain

Copyright (C) 2017 Mudassar Jalil et al. This is an open access article distributed under the Creative Commons Attribution License, which permits unrestricted use, distribution, and reproduction in any medium, provided the original work is properly cited.

\begin{abstract}
This paper deals with the boundary layer flow of electrically conducting dusty fluid over a stretching surface in the presence of applied magnetic field. The governing partial differential equations of the problem are transformed to nonlinear nondimensional coupled ordinary differential equations using suitable similarity transformations. The problem is now fully specified in terms of characterizing parameters known as fluid particle interaction parameter, magnetic field parameter, and mass concentration of dust particles. An exact analytical solution of the resulting boundary value problem is presented that works for all values of the characterizing parameters. The effects of these parameters on the velocity field and the skin friction coefficient are presented graphically and in the tabular form, respectively. We emphasize that an approximate numerical solution of this problem was available in the literature but no analytical solution was presented before this study.
\end{abstract}

\section{Introduction}

During the last few decades several exact analytical solutions are developed for the one-dimensional flow of Newtonian and non-Newtonian fluids; however, only limited success has been achieved for two- and three-dimensional flows. This is because of the nonlinear nature of the Navier Stokes equations for the viscous fluid and more complex constitutive equations for non-Newtonian fluids. Further difficulty arises when the governing equations are coupled nonlinear equations. Although numerous numerical and approximate techniques are available to compute solution of the fluid dynamics problems, the advantage of the exact analytical solution lies in mathematical ingenuity and the strength of the solution to explain physics of fluid flow. The exact analytical solution can also be considered as bench mark for further numerical and approximate investigations. Some of the exact solutions for the laminar flow of Newtonian and non-Newtonian fluids are given in [1-8].

Dusty fluid model flows have been a subject of special interest in recent studies due to their two-phase nature. This phenomenon occurs in fluid (liquid or gas) flows containing a distribution of solid particles. For example, motion of the dusty air in fluidization problems and the chemical process in which raindrops are formed by coalescence of small dust particles. Cosmic dust, which is formed due to the mixing of dust particles and gas, is primary precursor for planetary systems. The production of tails of comet 238 is due to emission of ionized gas and the dust particles from the comet body. The application of the dusty fluid can also be visualized in the processes such as nuclear reactor cooling, atmospheric fallout, powder technology, dust collection, acoustics, paint spray, rain erosion, sedimentation, performance of solid fuel rock nozzles, and guided missiles. These facts have expedited the consideration of modeling, solving, and analyzing the flow of dusty fluids.

Keeping interest in two-phase flows, many researchers worked the dusty fluid model for various flow configuration and the boundary conditions. However, realizing the difficulty of nonlinear coupled equations, no attempt has been made in working out any analytical solution. Therefore, the solutions given by them are through numerical and 
approximate schemes. A brief background history of dusty fluid is presented now. The study on laminar flow of dusty fluid is initiated by Saffman [9]. Chakrabarti [10] investigated the flow of dusty gas in the boundary layer region. The flow of dusty fluid over semi-infinite plate was discussed by Datta and Mishra [11]. Vajravelu and Nayfeh [12] analyzed the hydromagnetic flow of dusty fluid over stretching surface in the presence of suction velocity. Gireesha et al. [13] obtained the numerical solution for the two-dimensional boundary layer flow and heat transfer of dusty fluid over stretching surface. Numerical solution of MHD flow and heat transfer of dusty fluid over a linearly stretching sheet was given by Gireesha et al. [14]. Ramesh et al. [15] considered MHD boundary layer flow of dusty fluid over inclined stretching sheet. Later on, Gireesha et al. [16] examined thermal radiation effects of MHD flow of dusty fluid over exponentially stretching sheet. We once again mention that all of these studies involve numerical or approximate solutions, whereas no exact analytical solution is provided so far.

The study of MHD flow is significant due to its many engineering applications such as the cooling of reactors, electrostatic precipitation, power generators, MHD pumps, accelerators, petroleum industry, and the design of heat exchangers. Furthermore, MHD flow plays important role in petroleum industries, agriculture, geophysics, astrophysics, solar physics, metrology, and the motion of earth's core. Keeping in view the importance of MHD flow and the importance of exact solution, we present exact analytical solution for the MHD boundary layer flow of dusty fluid over a stretching surface. Another distinctive aspect of this study is the presentation of mathematical result for the nonlinear coupled partial differential equations which are usually handled numerically (as has been in the case of dusty fluid). The mathematical methodology consists of converting the modeled equations into self-similar form characterized by dusty and magnetic parameters, using the known similarity transformations. The coupled equations are then solved analytically based on the solution given by Crane [1]. The exact solution is calculated for the flow field and the skin friction in terms of the characterizing parameters such as mass concentration of dust particles, the fluid particle interaction parameter, and the magnetic parameter.

\section{Description of the Problem}

Consider a steady of two-dimensional laminar boundary layer flow of an electrically conducting viscous incompressible dusty fluid over a semi-infinite surface. The surface is stretching with the velocity $u_{w}(x)=c x$, where the positive constant $c$ is the stretching rate. Cartesian coordinate system is located in such a way that $x$-axis and $y$-axis are taken along (and normal to) the surface, respectively, while the origin of the system is located at the leading edge. The shape of dust particles is assumed to be spherical with uniform size and constant number density. Considering these physical assumptions, along with the boundary layer approximations, the governing equations for the flow of dusty fluid together with the boundary conditions are given as (see [14])

$$
\begin{aligned}
\frac{\partial u}{\partial x}+\frac{\partial v}{\partial y} & =0, \\
u \frac{\partial u}{\partial x}+v \frac{\partial u}{\partial y} & =v \frac{\partial^{2} u}{\partial y^{2}}+\frac{\gamma}{\tau}\left(u_{p}-u\right)-\frac{\sigma B_{0}^{2}}{\rho} u, \\
\frac{\partial u_{p}}{\partial x}+\frac{\partial v_{p}}{\partial y} & =0, \\
u_{p} \frac{\partial u_{p}}{\partial x}+v_{p} \frac{\partial u_{p}}{\partial y} & =\frac{1}{\tau}\left(u-u_{p}\right), \\
y & =0 ; \quad u=u_{w}(x), \quad v=0, \\
y & \longrightarrow \infty ; \quad u=0, u_{p}=0, \quad v_{p}=v
\end{aligned}
$$

where $u$ and $u_{p}$ (similarly $v$ and $v_{p}$ ) are the $x$ and $y$ components of fluid and the dust particles velocity, respectively. Parameter $\gamma=m N / \rho$ denotes the mass concentration of dust particles; $\tau=m / K$ is the relaxation time of particle phase and $\rho, \nu, \sigma$, and $B_{0}$ represent the density, kinematic viscosity, electrical conductivity of the fluid, and induced magnetic field, respectively. The terms appearing in $\gamma$ and $\tau$ are the Stokes resistance $(K)$, the number density $(N)$, and the mass of the dust particle $(m)$.

We define the following similarity transformations [14]:

$$
\begin{aligned}
\eta & =\sqrt{\frac{c}{v}} y, \\
u & =c x f^{\prime}(\eta), \\
v & =-\sqrt{c \nu} f(\eta), \\
u_{p} & =c x g^{\prime}(\eta), \\
v_{p} & =-\sqrt{c v} g(\eta),
\end{aligned}
$$

where prime $\left(^{\prime}\right)$ represents differentiation with respect to $\eta$. Introducing transformations (2) in (1), we get the following self-similar boundary value problem:

$$
\begin{aligned}
f^{\prime \prime \prime}+f f^{\prime \prime}-f^{\prime 2}+\beta \gamma\left(g^{\prime}-f^{\prime}\right)-M f^{\prime} & =0, \\
g g^{\prime \prime}-g^{\prime 2}+\beta\left(f^{\prime}-g^{\prime}\right) & =0, \\
f(0) & =0, \\
f^{\prime}(0) & =1, \\
f^{\prime}(\infty) & =0, \\
g^{\prime}(\eta) & =0, \\
g(\eta) & =f(\eta) \\
& \text { as } \eta \longrightarrow \infty,
\end{aligned}
$$


TABLE 1: Comparison of skin friction coefficient for various values of $\beta$ and $M$ with Gireesha et al. [17].

\begin{tabular}{ccccc}
\hline$M$ & Gireesha et al. [17] & Exact solution & Gireesha et al. [17] & Exact solution \\
\hline 0.2 & $\beta=0$ & 1.000000 & 1.034 & 1.033505 \\
0.2 & 1.000 & 1.095445 & 1.126 & 1.126114 \\
0.5 & 1.095 & 1.224745 & 1.252 & 1.252251 \\
1.0 & 1.224 & 1.414214 & 1.438 & 1.438101 \\
1.2 & 1.414 & 1.483240 & 1.506 & 1.506032 \\
1.5 & 1.483 & 1.581139 & 1.602 & 1.602540 \\
2.0 & 1.581 & 1.732051 & 1.751 & 1.751609 \\
\hline
\end{tabular}

where $\beta$ and $M$ are the fluid particle interaction parameter and magnetic parameter, respectively, and are defined by

$$
\begin{aligned}
\beta & =\frac{1}{c \tau}=\frac{K}{c m}, \\
M & =\frac{\sigma B_{0}{ }^{2}}{c \rho} .
\end{aligned}
$$

The skin friction coefficient $C_{f}$ and the shear stress $\tau_{w}$ are defined as

$$
\begin{aligned}
C_{f} & =\frac{-\tau_{w}}{\rho u_{w}{ }^{2}}, \\
\tau_{w} & =\left.\mu\left(\frac{\partial u}{\partial y}\right)\right|_{y=0} .
\end{aligned}
$$

Using transformation (2), the dimensionless skin friction coefficient is defined by $\operatorname{Re}_{x}{ }^{-1 / 2} C_{f}=-f^{\prime \prime}(0)$, where $\mathrm{Re}_{x}=$ $c x^{2} / v$ is the local Reynolds number.

In the next section, we will present the exact analytical solution of these equations.

\section{Exact Analytical Solution}

Based upon the solution given by Crane [1], we propose that the nonlinear coupled equations (3) admit exponentially decaying solution of the form

$$
\begin{aligned}
& f=\alpha_{1}+\alpha_{2} e^{-\alpha_{3} \eta}, \\
& g=\alpha_{4}+\alpha_{5} e^{-\alpha_{6} \eta},
\end{aligned}
$$

where $\alpha_{i, s}$ (for $i=1, \ldots, 6$ ) are arbitrary constants. The values of these constants can be determined by putting the solution (6) in (3). This yields

$$
\begin{aligned}
& \alpha_{1}=-\alpha_{2}=\alpha_{4}=\frac{1}{\zeta}, \\
& \alpha_{3}=\alpha_{6}=-\zeta \\
& \alpha_{5}=-\frac{\beta}{\zeta(1+\beta)},
\end{aligned}
$$

where the term $\zeta$ is given as

$$
\zeta=\sqrt{1+M+\frac{\beta \gamma}{1+\beta}} .
$$

Substituting the values of $\alpha_{i, s}$ (for $i=1, \ldots, 6$ ) from (7) into (6), we get closed form exact solution:

$$
\begin{aligned}
& f=\frac{1}{\zeta}\left(1-e^{-\zeta \eta}\right), \\
& g=\frac{1}{\zeta}\left(1-\frac{\beta}{1+\beta} e^{-\zeta \eta}\right),
\end{aligned}
$$

It is worth noting that the solution given in (9) works for all values of $\beta, \gamma$, and $M$. The physical quantities like the velocities of fluid and the dust particles and the skin friction coefficient are now expressed as

$$
\begin{aligned}
f^{\prime}(\eta) & =e^{-\zeta \eta}, \\
g^{\prime}(\eta) & =\frac{\beta}{1+\beta} e^{-\zeta \eta}, \\
-f^{\prime \prime}(0) & =\zeta=\sqrt{1+M+\frac{\beta \gamma}{1+\beta}} .
\end{aligned}
$$

The numerical solution of (3) exists in the literature, but the exact analytical closed from solution is presented here for the first time. Now using these results one can easily interpret the effects of dusty fluid parameters on the physical quantities without using any numerical scheme. It will not be out of place to make a comparison with the numerical results presented by Gireesha et al. [17] using Runge Kutta Fehlberg fourth-fifth-order method (RKF45 Method). An excellent match is found between the two results as shown in Table 1.

We also present the graphs for velocity profiles (Figures 1(a) and 1(b)) for different values of parameters $M$ and $\beta$ and compare these results with the numerical results given in [14]. This comparison will further validate the authenticity of the two solutions. From Figure 1, we observe that both the fluid velocity and the velocity of dust particles decrease with increasing $M$. This is because increasing magnetic field the opposing Lorentz force increases resulting in the decrease of the fluid velocity. Effects of fluid particle interaction $\beta$, mass concentration of dust particles $\gamma$, and the magnetic parameter 


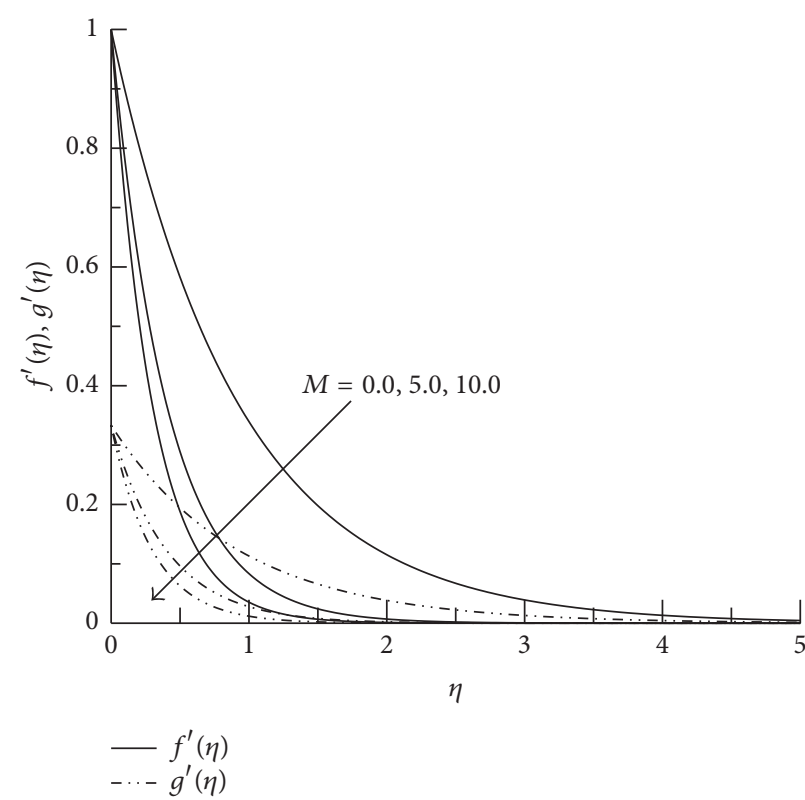

(a)

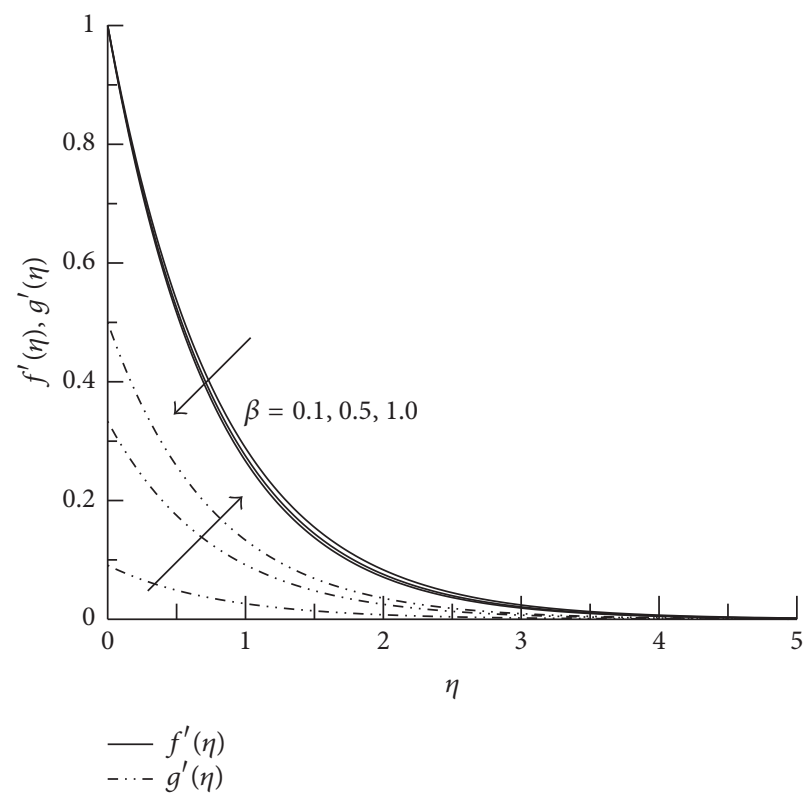

(b)

FIGURE 1: Effects of $M(\mathrm{a})$ and $\beta$ (b) on the velocity profiles.

TABLE 2: Skin friction coefficient for various values of $\beta, \gamma$, and $M$.

\begin{tabular}{lccc}
\hline$\gamma$ & $\beta$ & $M$ & $-f^{\prime \prime}(0)$ \\
\hline 0.2 & & & 1.437591 \\
0.5 & 0.5 & 1.0 & 1.471960 \\
1.0 & & & 1.527525 \\
\hline \multirow{2}{*}{0.1} & 0.2 & & 1.420094 \\
& 0.5 & 1.0 & 1.425950 \\
\hline & 1.0 & & 1.431782 \\
0.1 & & 2.0 & 1.741647 \\
& 0.5 & 5.0 & 2.456284 \\
& & 10.0 & 3.321646 \\
\hline
\end{tabular}

$M$ on the skin friction coefficient are given in Table 2. It is observed that skin friction increases with increasing values of $\beta, \gamma$, and $M$. This happens because increase in these parameters produces resistance to the flow and the skin friction increases.

\section{Conclusion}

An exact analytical solution for the MHD boundary layer flow of dusty fluid over a linearly stretching surface is presented. This result is uniformly valid for all values of physical characterizing parameters arising in the flow of dusty fluid. Expressions for the velocity and the skin friction are presented for the flow configuration. The results are compared with the existing study giving good agreement. This work provides a base for further research in undertaking analytical solutions of dusty fluid flow over stretching surface. Exact solution for MHD flow for viscoelastic non-Newtonian fluid can be obtained using the analysis of this paper that will be reported in a subsequent study.

\section{Nomenclature}

$B_{0}: \quad$ Induced magnetic field $\left(\mathrm{kg}^{-1} \mathrm{~s}^{-2} \mathrm{~A}^{-1}\right)$

$c: \quad$ Stretching rate $\left(\mathrm{s}^{-1}\right)$

$C_{f}: \quad$ Skin friction coefficient

$f$ : $\quad$ Dimensionless stream function for fluid velocity

g: Dimensionless stream function for

particle velocity

$K: \quad$ Stokes resistance $\left(\mathrm{kg} \mathrm{s}^{-1}\right)$

$m: \quad$ Mass of the dust particle $(\mathrm{kg})$

M: $\quad$ Magnetic parameter

$N$ : Number density of dust particle $\left(\mathrm{m}^{-3}\right)$

$\mathrm{Re}_{x}: \quad$ Local Reynolds number

$u_{w}$ : $\quad$ Stretching velocity $\left(\mathrm{m} \mathrm{s}^{-1}\right)$

$u, v$ : Components of fluid velocity along $x$ - and $y$-axes $\left(\mathrm{m} \mathrm{s}^{-1}\right)$

$u_{p}, v_{p}$ : Components of particle velocity along $x$ and $y$-axes $\left(\mathrm{m} \mathrm{s}^{-1}\right)$

$x, y$ : Cartesian coordinates ( $x$-axis is aligned along the stretching surface and $y$-axis is normal to it) (m).

\section{Greek Symbols}

$\alpha_{i}$ : Arbitrary constants

$\beta$ : Fluid particle interaction parameter

$\eta$ : Similarity variable

$\gamma$ : Mass concentration of dust particles 
$v$ : Kinematic viscosity of the fluid $\left(\mathrm{m}^{2} \mathrm{~s}^{-1}\right)$

$\mu$ : Dynamic viscosity of the fluid $\left(\mathrm{kg} \mathrm{m}^{-1} \mathrm{~s}^{-1}\right)$

$\rho$ : Fluid density $\left(\mathrm{kg} \mathrm{m}^{-3}\right)$

$\tau$ : Relaxation time of particle phase (s)

$\sigma$ : Electrical conductivity of the fluid $\left(\mathrm{kg}^{-1} \mathrm{~m}^{-3} \mathrm{~s}^{3} \mathrm{~A}^{2}\right)$

$\tau_{w}$ : Shear stress at the surface $\left(\mathrm{kg} \mathrm{m}^{-1} \mathrm{~s}^{-2}\right)$

$\psi$ : Stream function $\left(\mathrm{m}^{2} \mathrm{~s}^{-1}\right)$.

\section{Superscripts}

I: Differentiation with respect to $\eta$

Subscripts

p: Dust particle

$w$ : Condition at surface.

\section{Competing Interests}

The authors declare that they no conflict of interests regarding the publication of this paper.

\section{References}

[1] L. J. Crane, "Flow past a stretching plate," Zeitschrift für angewandte Mathematik und Physik ZAMP, vol. 21, no. 4, pp. 645-647, 1970.

[2] B. Siddappa and S. Abel, "Non-Newtonian flow past a stretching plate," Zeitschrift für Angewandte Mathematik und Physik, vol. 36, no. 6, pp. 890-892, 1985.

[3] H. I. Andersson, "MHD flow of a viscoelastic fluid past a stretching surface," Acta Mechanica, vol. 95, no. 1, pp. 227-230, 1992.

[4] H. I. Andersson, "An exact solution of the Navier-Stokes equations for magnetohydrodynamic flow," Acta Mechanica, vol. 113, no. 1-4, pp. 241-244, 1995.

[5] H. I. Andersson, "Slip flow past a stretching surface," Acta Mechanica, vol. 158, no. 1-2, pp. 121-125, 2002.

[6] E. Magyari and B. Keller, "Exact solutions for self-similar boundary-layer flows induced by permeable stretching walls," European Journal of Mechanics. B. Fluids, vol. 19, no. 1, pp. 109122,2000

[7] M. Jalil, S. Asghar, and M. Mushtaq, "Analytical solutions of the boundary layer flow of power-law fluid over a power-law stretching surface," Communications in Nonlinear Science and Numerical Simulation, vol. 18, no. 5, pp. 1143-1150, 2013.

[8] M. Jalil and S. Asghar, "Flow of power-law fluid over a stretching surface: a Lie group analysis," International Journal of NonLinear Mechanics, vol. 48, pp. 65-71, 2013.

[9] P. G. Saffman, "On the stability of laminar flow of a dusty gas," Journal of Fluid Mechanics, vol. 13, pp. 120-128, 1962.

[10] K. M. Chakrabarti, "Note on boundary layer in a dusty gas," AIAA Journal, vol. 12, no. 8, pp. 1136-1137, 1974.

[11] N. Datta and S. K. Mishra, "Boundary layer flow of a dusty fluid over a semi-infinite flat plate," Acta Mechanica, vol. 42, no. 1-2, pp. 71-83, 1982.
[12] K. Vajravelu and J. Nayfeh, "Hydromagnetic flow of a dusty fluid over a stretching sheet," International Journal of Non-Linear Mechanics, vol. 27, no. 6, pp. 937-945, 1992.

[13] B. J. Gireesha, G. K. Ramesh, H. J. Lokesh, and C. S. Bagewadi, "Boundary layer flow and heat transfer of a dusty fluid over a stretching vertical surface," Applied Mathematics, vol. 2, pp. 475-481, 2011.

[14] B. J. Gireesha, G. S. Roopa, H. J. Lokesh, and C. S. Bagewadi, "MHD flow and heat transfer of a dusty fluid over a stretching sheet," International Journal of Physical and Mathematical Sciences, vol. 3, pp. 171-182, 2012.

[15] G. K. Ramesh, B. J. Gireesha, and C. S. Bagewadi, "Heat transfer in MHD dusty boundary layer flow over an inclined stretching sheet with non-uniform heat source/sink," Advances in Mathematical Physics, vol. 2012, Article ID 657805, 13 pages, 2012.

[16] B. J. Gireesha, G. M. Pavithra, and C. S. Bagewadi, “Thermal radiation effect on MHD flow of a dusty fluid over an exponentially stretching sheet," International Journal of Engineering Research \& Technology, vol. 2, pp. 1-11, 2013.

[17] B. J. Gireesha, G. K. Ramesh, and C. S. Bagewadi, "Heat transfer in MHD flow of a dusty fluid over a stretching sheet with viscous dissipation," Advances in Applied Science Research, vol. 3, no. 4, pp. 2392-2401, 2012. 


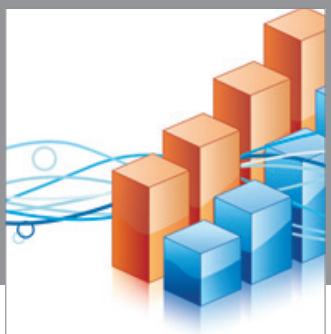

Advances in

Operations Research

vatem alat4

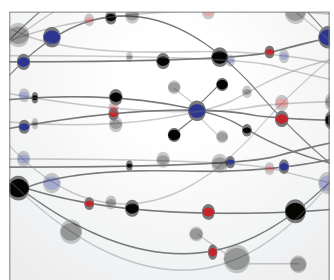

\section{The Scientific} World Journal
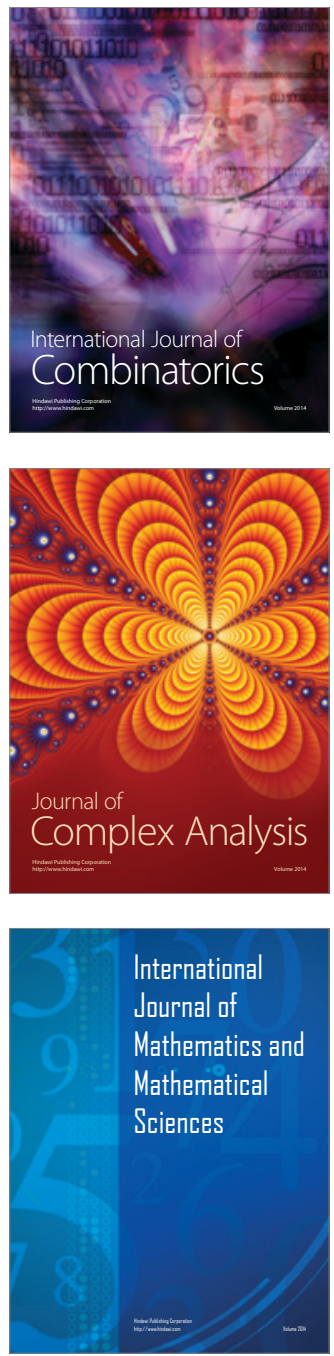
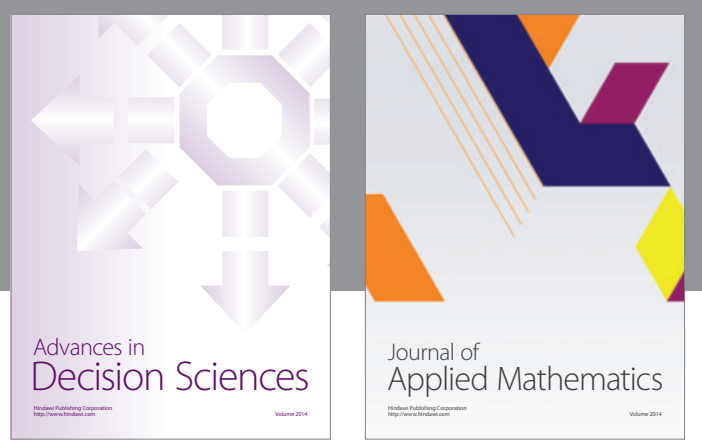

Algebra

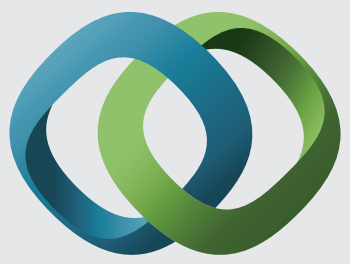

\section{Hindawi}

Submit your manuscripts at

https://www.hindawi.com
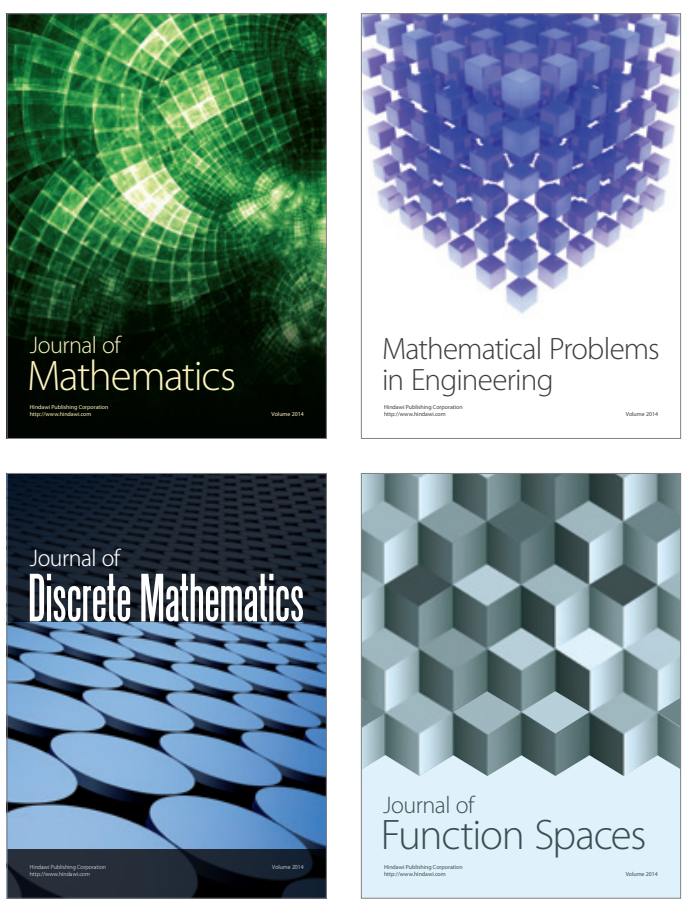

Mathematical Problems in Engineering
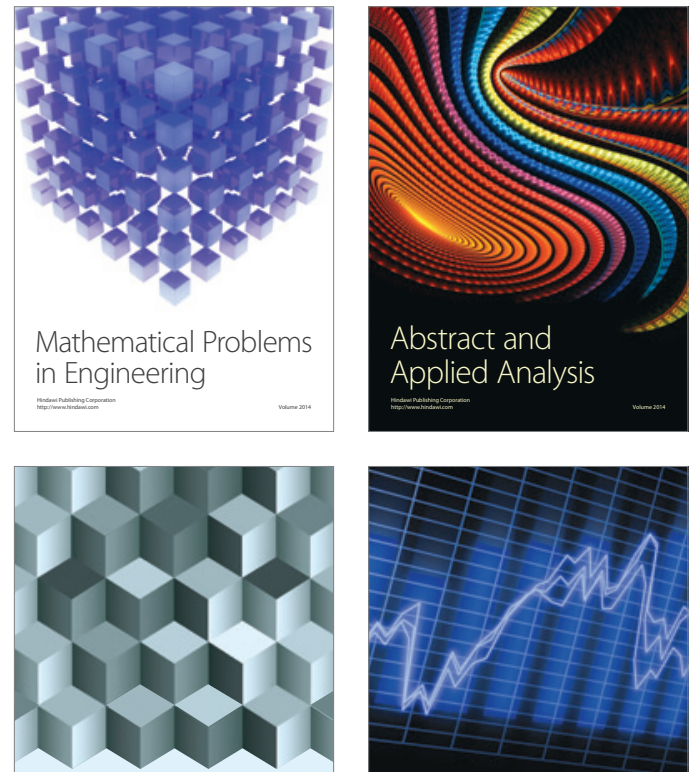

Journal of

Function Spaces

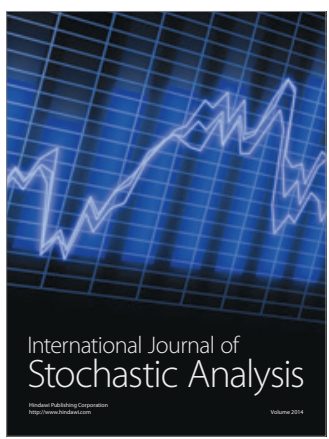

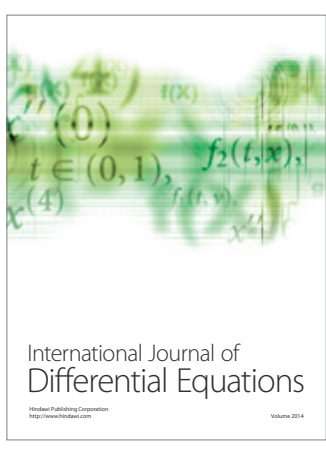
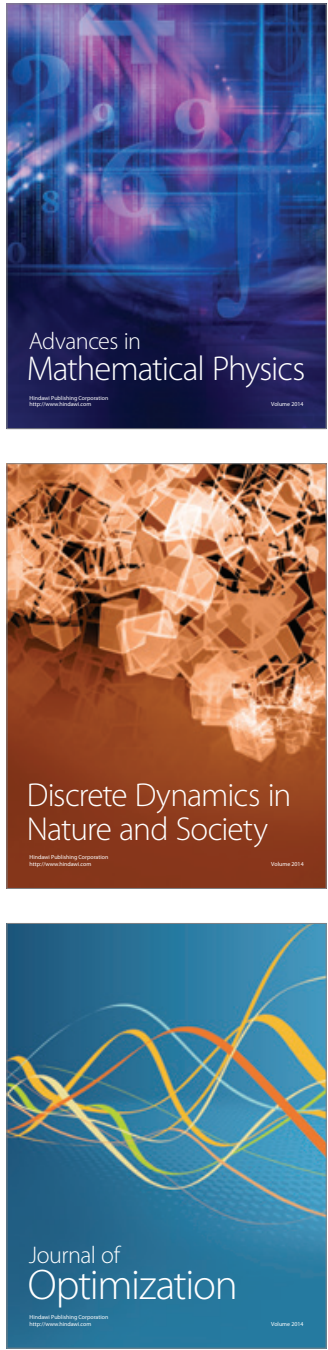